\title{
National Health Service Principles as Experienced by Vulnerable London Migrants in "Austerity Britain": A Qualitative Study of Rights, Entitlements, and Civil- Society Advocacy
}

\author{
Elham Rafighi ${ }^{1}$, Shoba Poduval ${ }^{1}$, Helena Legido-Quigley ${ }^{1,2}$, Natasha Howard ${ }^{{ }^{*}}$
}

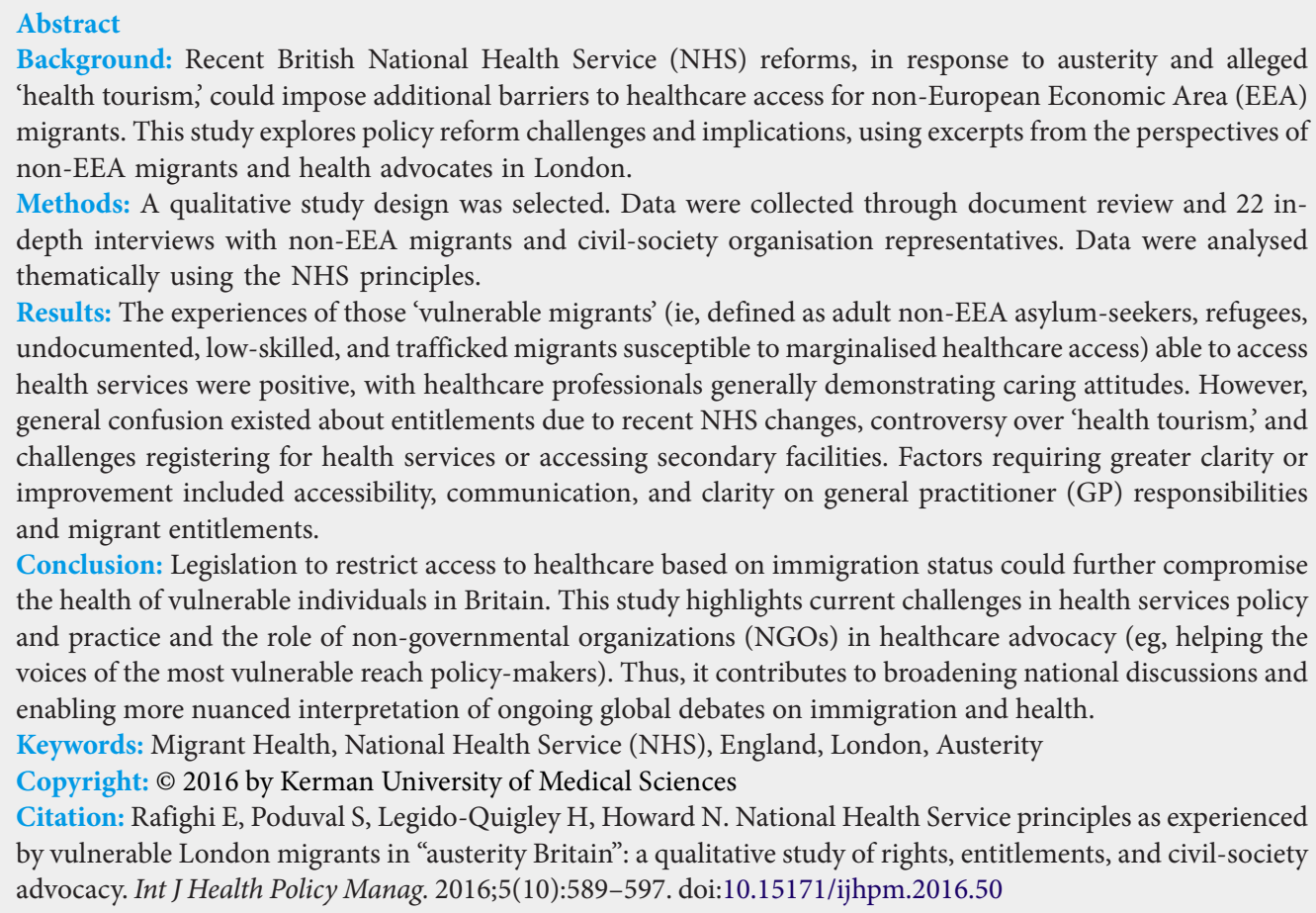

Background: Recent British National Health Service (NHS) reforms, in response to austerity and alleged 'health tourism,' could impose additional barriers to healthcare access for non-European Economic Area (EEA) migrants. This study explores policy reform challenges and implications, using excerpts from the perspectives of non-EEA migrants and health advocates in London.

Methods: A qualitative study design was selected. Data were collected through document review and 22 indepth interviews with non-EEA migrants and civil-society organisation representatives. Data were analysed thematically using the NHS principles.

Results: The experiences of those 'vulnerable migrants' (ie, defined as adult non-EEA asylum-seekers, refugees, undocumented, low-skilled, and trafficked migrants susceptible to marginalised healthcare access) able to access health services were positive, with healthcare professionals generally demonstrating caring attitudes. However, general confusion existed about entitlements due to recent NHS changes, controversy over 'health tourism, and challenges registering for health services or accessing secondary facilities. Factors requiring greater clarity or improvement included accessibility, communication, and clarity on general practitioner (GP) responsibilities and migrant entitlements.

Conclusion: Legislation to restrict access to healthcare based on immigration status could further compromise the health of vulnerable individuals in Britain. This study highlights current challenges in health services policy and practice and the role of non-governmental organizations (NGOs) in healthcare advocacy (eg, helping the voices of the most vulnerable reach policy-makers). Thus, it contributes to broadening national discussions and enabling more nuanced interpretation of ongoing global debates on immigration and health.

Keywords: Migrant Health, National Health Service (NHS), England, London, Austerity

Copyright: @ 2016 by Kerman University of Medical Sciences

Citation: Rafighi E, Poduval S, Legido-Quigley H, Howard N. National Health Service principles as experienced by vulnerable London migrants in "austerity Britain": a qualitative study of rights, entitlements, and civil-society advocacy. Int J Health Policy Manag. 2016;5(10):589-597. doi:10.15171/ijhpm.2016.50

\section{Article History:}

Received: 17 October 2015 Accepted: 30 April 2016 ePublished: 8 May 2016

\section{Key Messages}

\section{Implications for policy makers}

- Interviews with vulnerable migrants and healthcare advocates indicated issues with confusing or unnecessary administrative demands, gatekeeper communications, and confidentiality/data protection fears within the national context of immigration fears and austerity-related entitlement changes.

- $\quad$ Restricting healthcare access based on immigration status could further compromise the health of vulnerable individuals, with consequences for public health equity and social cohesion.

Implications for the public

This research gives voice to vulnerable migrants, many leaving situations of significant deprivation and danger, who describe their experiences with British National Health Services (NHS). National political discourse, in which non-European immigrants are less deserving or must be prevented from taking advantage, is divisive and one-sided. Findings help broaden the national discussion, enabling more nuanced interpretation of ongoing global debates on migration and health.

\section{Background}

British Prime Minister Cameron's 'age of austerity' has been characterised by unprecedented public services and funding cuts, high unemployment, reductions in contracted hours, emergence of 'zero-hours' contracts and reductions in pay, pensions, and entitlements. ${ }^{1,2}$ Austerity has broad effects and health systems under pressure often reduce public health and healthcare spending (eg, by cutting services, limiting eligibility, and shifting from government to private-sector delivery). ${ }^{3}$ Austerity measures were introduced following the British Government's spending review in 2010 and included $£ 81$ bn in cuts to public spending over four years. ${ }^{4}$ Failure to meet targets by 2014 extended these measures until at least 2018, suggesting a decade of austerity. ${ }^{5}$ Further cuts 
of $£ 11.5$ bn and $£ 20$ bn were announced in 2013 and 2015 spending reviews, respectively. ${ }^{6}$ After continuous healthcare budget growth, with an average 6\% increase from 1999 to 2007 , healthcare fell to $0.1 \%$ of national spending for the next four years. ${ }^{7}$ Following housing benefits cuts, approximately 10000 families became homeless. ${ }^{7}$ While health in Europe has improved in recent years, austerity measures can exacerbate existing inequalities (eg, those in richer areas in the United Kingdom will live an average seven years longer than those in deprived areas). ${ }^{8}$

Considerable literature documents migrant and other ethnic minority experiences with the National Health Service (NHS) before and during austerity, showing many inequities as systemic and longstanding. ${ }^{9-18}$ While austerity measures are not responsible for inequities in service access and quality, combined with rapid recent demographic changes, patterns of social exclusion, and increasingly restrictive immigration policies, austerity leaves some migrants increasingly vulnerable to inequitable health services provision., ${ }^{79-21}$

The British NHS, established in 1948, is a publicly-funded healthcare system providing universal coverage for users. ${ }^{22}$ Primarily funded through general taxation, NHS healthcare is provided on the basis of need rather than ability to pay. ${ }^{23}$ The Health and Social Care Act, effective from April 1, 2013 (Table 1), transformed healthcare provisions and access through a revised definition of qualifying residency requiring that non-European Economic Area (EEA) migrants have indefinite leave to remain in Britain before accessing free NHS care. The Immigration Act 2014 modified how nonEEA migrants access NHS services, ending free primary care for visitors and implementing registration and tracking at NHS registration..$^{24,25}$ From April 6, 2015, a new immigration health surcharge came into force under the Immigration Act
2014, requiring all non-EEA nationals visiting Britain for more than 6 months to pay a $£ 200$ annual surcharge ( $£ 150$ for students), while short-term visitors were to pay the NHS at point of use. ${ }^{26}$ The Department of Health (DoH) has not yet extended this charging regime beyond hospitals, so treatment in Accident and Emergency (A\&E) departments and general practice surgeries remains free for all. ${ }^{27}$ The NHS is required to recover charges, set at $150 \%$ of national tariffs for those from outside the EEA, from all individuals not deemed exempt. ${ }^{27}$ These NHS reforms impact health services accessibility, eliciting concerns about the extent alterations may violate human rights and issues around patient records and confidentiality. ${ }^{28}$ Access includes receipt of healthcare and consideration of the process and quality of care received..$^{29}$ It is affected by both intrinsic (eg, socio-cultural beliefs, ${ }^{29}$ language, ${ }^{13}$ literacy ${ }^{30-32}$ ) and extrinsic factors (eg, service quality, service location ${ }^{29,33}$ ). Equitable access requires information that is relevant, timely, and useful, and an enabling environment that treats service-users with respect and dignity. ${ }^{14,34}$

A Home Office consultation indicated public concern that migrant NHS entitlements were 'too generous,'35 while ministers raised 'health tourism' fears that non-residents purposefully travel to the United Kingdom for free healthcare. Health tourism has gained UK policy-maker attention as a drain on the NHS. ${ }^{28,35,36}$ However, opponents argue that assertions of rampant health tourism are politicallymotivated and baseless. ${ }^{37,38}$ Hanefeld and colleagues used the Office of National Statistics IPS dataset 2000-2010 to show that inbound travel of foreign patients has remained constant, with a substantial increase in UK residents travelling abroad for medical treatment. ${ }^{37}$ Similarly, doctors of the world (DoW) service-user data shows most have lived in the United

Table 1. Timeline of NHS Reforms

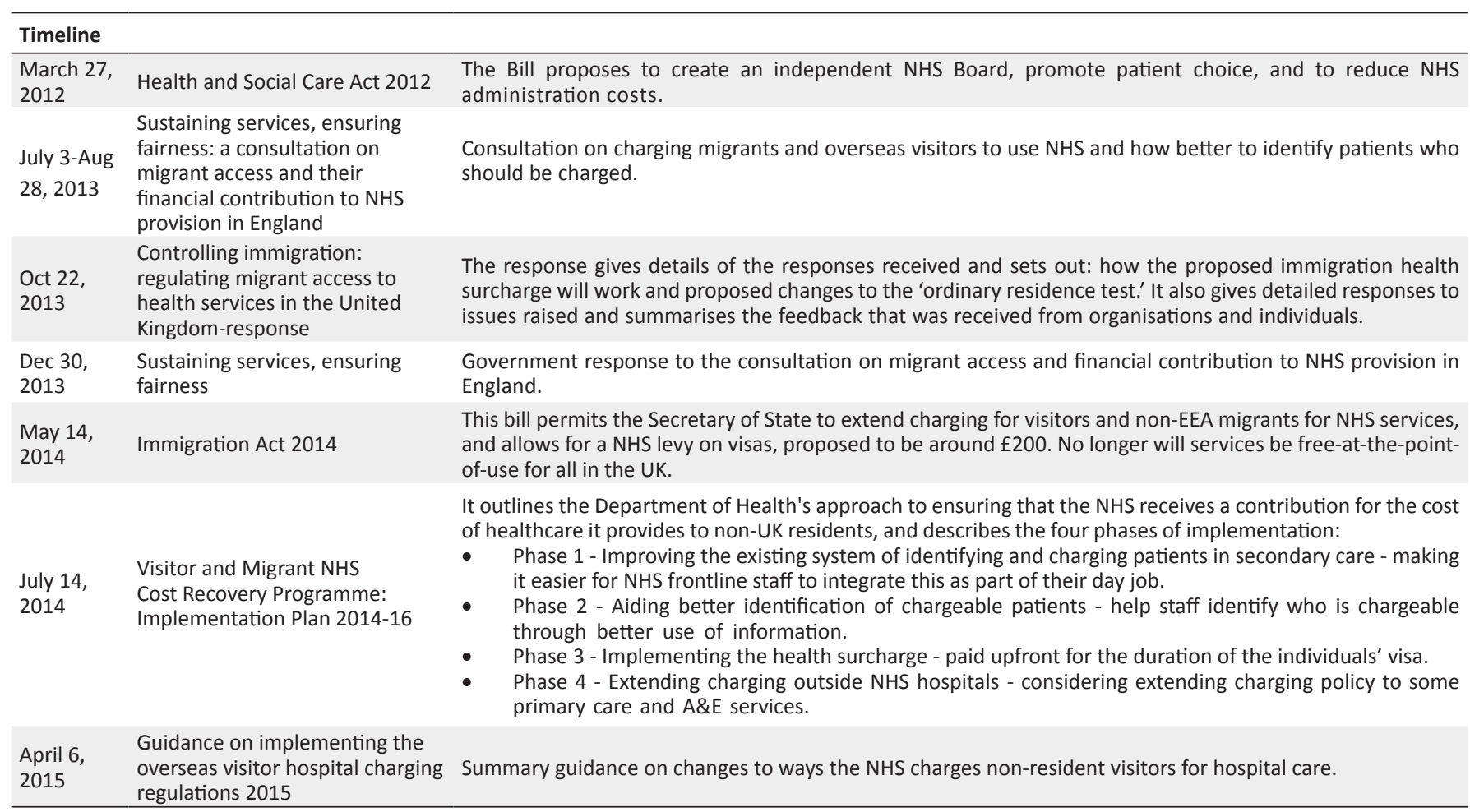

Abbreviations: NHS, National Health Service; EEA, European Economic Area; A\&E, accident and emergency.

Source: Reference 36 and https://www.gov.uk/government/publications. 
Kingdom for three years before coming for assistance. ${ }^{30}$ Introduction of NHS reforms bars migrants from accessing primary and secondary care, increasing their exclusion from health services. ${ }^{30}$ Access to free NHS care was traditionally subject to users being 'ordinarily resident' in the United Kingdom, the leading case for which is Shah versus Barnet. ${ }^{35,39}$ In 2011, the DoH defined ordinarily resident as: "Living lawfully in the United Kingdom voluntarily and for settled purposes as part of the regular order of their life for the time being. ${ }^{28}$ From April 2015, requirements for being ordinarily resident in the United Kingdom changed to include only those non-EEA nationals with 'indefinite leave to remain' immigration status. $^{27}$

While many services are legally available to undocumented migrants in Britain, persistent practical barriers may prevent vulnerable migrants from accessing the care to which they are entitled. ${ }^{40}$ NHS reforms affect access to free secondary and tertiary treatment for failed asylum-seekers, undocumented migrants (ie, non-EEA nationals without immigration permission to be in the United Kingdom), visitors (ie, individuals of any nationality who temporarily visit the United Kingdom), and British expatriates. ${ }^{28}$ Rules and regulation of entitlements are unclear, leading to confusion among providers and service-users. ${ }^{38,40-43}$ Asylum-seekers and undocumented migrants may fear that if they use health services, they will be reported to authorities. Such reluctance to use health services may result in the delayed treatment of infections that endanger wider population health, inappropriate use of costly emergency services, barriers in registering with general practitioners (GPs), and lack of engagement with or awareness of vital health promotion activities. ${ }^{44}$

The British Medical Association (BMA), the UK doctors' trade union, issued a public statement of members concerns regarding vulnerable migrants, based on humanitarian, economic, and public health arguments. ${ }^{24}$ Specifically, the BMA supports timely provision of appropriate care to vulnerable patients and doctors should not be expected to assess patient eligibility for free NHS care. It is crucial that health professionals be aware of entitlements in place for vulnerable migrants and of their responsibilities in treating and referring them. Table 2 summarises key points of published entitlement guidance.

This study aimed to explore ways policy and operational changes to NHS principles under austerity were experienced by non-EEA migrants. A related paper focuses on barriers to accessing primary healthcare. ${ }^{18}$
Methods

Design and Setting

A critical theory anchored qualitative study design with a social justice perspective was selected, ${ }^{45-47}$ including in-depth interviews with vulnerable migrants and civilsociety advocates informed by peer-reviewed literature and policy documentation. ${ }^{48} \mathrm{~A}$ critical approach, informed by social justice principles of equity, access, participation, and harmony, ${ }^{49}$ was chosen for its acknowledgment of historic political, social, and economic power imbalances relevant to migrant research. ${ }^{47}$ Interviews were selected as best for engaging participants and producing narrative experiences. ${ }^{50}$ Literature and documentation provided context and clarification.

The research question was 'What are the perspectives and experiences described by vulnerable migrants and their advocates in London within the context of NHS policy and operational changes under austerity?' Vulnerable migrants were defined as adult non-EEA asylum-seekers, refugees, undocumented, low-skilled and trafficked migrants susceptible to marginalised healthcare access. ${ }^{44}$ Using the term 'vulnerable' is not to downplay agency and strengths, or suggest victimhood, but rather to clarify their legal position as one of potential vulnerability. Data were collected between June and September 2014.

\section{Data Collection}

In-depth face-to-face interviews, using purposive and snowball sampling, were organised with vulnerable migrant service-users and representatives of civil-society advocacy organisations at the DoW clinic in London, UK. Purposive sampling was chosen because vulnerable migrants are hard to reach through conventional methods such as invitations through public services. Many did not have contact details registered. Some are defensive and mistrusting of researchers. DoW service-users had an existing relationship and were therefore, easier to access and interview. Interviews were, conducted weekly during June-July 2014 at the DoW clinic. Participants were recruited from consecutive consultations and sample composition is described in Table 3. Snowball sampling was used when participants attended with friends or relatives in similar circumstances who were asked if they would like to participate. Sample size was dictated by time and resources.

SP and ER, both trained in qualitative interviewing, conducted interviews as part of MSc research at the London

Table 2. Key Points From Entitlement Guidance

1. All asylum-seekers and refugees are entitled to register with a GP and receive free NHS hospital treatment.

2. GP practices retain discretion to register refused asylum-seekers and provide them health services to the same extent that they have this discretion in

2. registering and providing services to any patient, regardless of residency status.

Treatment of certain specified communicable diseases (eg, tuberculosis, hepatitis B, measles), compulsory mental health treatment, treatment provided in event of an accident, and emergency department services are exempt from charges for all patients.

4. Health professionals must not discriminate against asylum-seekers or refused asylum-seekers by unfairly prioritising other patients over them.

5. In England, refused asylum-seekers and asylum-seekers not receiving benefits may still be entitled to free prescriptions. Prescription charges have been abolished in Wales, Scotland, and Northern Ireland.

6. Different entitlements to free hospital treatment for refused asylum-seekers exist in each UK nation.

7. It is not the responsibility of doctors to make decisions concerning the eligibility of patients to access free NHS hospital care.

8. Refused asylum-seekers who were undergoing a course of hospital treatment at the time their claim for asylum was rejected are entitled to undergo 8. that period of treatment free-of-charge until completion.

Abbreviations: NHS, National Health Service; GP, general practitioner. 
Table 3. Summary of Study Participants

\begin{tabular}{lccc}
\hline Migrants' Country of Origin & Male & Female & Total \\
\hline Belarus & 1 & 0 & 1 \\
Brazil & 0 & 1 & 1 \\
Sierra Leone & 1 & 0 & 1 \\
Ghana & 1 & 0 & 5 \\
India & 4 & 1 & 1 \\
Moldova & 1 & 0 & 2 \\
Philippines & 0 & 2 & 3 \\
Uganda & 0 & 3 & 1 \\
Vietnam & 1 & 0 & 16 \\
\hline Total & 9 & Advocacy Approaches & Recommendations \\
\hline NGOs & Participants & Coalition of charities, policy advocates, and researchers \\
\hline DoW & 4 (face-to-face) & Policy and case-based advocacy & Research into UK Latin American communities \\
Migrant rights network & 1 (face-to-face) & Policy advocacy & \\
Medsin & 1 (telephone) & Student-led advocacy & \\
Total & 6 & & Empower health professionals to advocate for vulnerable migrants \\
\hline
\end{tabular}

Abbreviations: NGO, non-governmental organization; DoW, doctors of the world.

School of Hygiene and Tropical Medicine, London, UK. A topic guide was developed and agreed by all authors. Interviews were conducted in English. Due to wide linguistic diversity and variable confidence in spoken English, most attended services with translator companions (eg, family members). Interviewers avoided interviewing participants in the presence of companions to preserve confidentiality and data quality. However, three participants requested their companions remain present to translate, which was agreed based on interviewer judgment that informed consent was freely given and their presence would not adversely affect data collection. Interviews lasted approximately one hour and were conducted, digitally recorded, and transcribed by SP and ER. Published literature was identified through PubMed, PLoS, and NHS evidence database searches, while policy documents, institutional reports, guidelines, and media articles were identified through Google searches, hand searching Gov.uk, NHS England, and BMA websites, and non-governmental organization (NGO) representatives' recommendations.

\section{Analysis}

Transcript and document data were managed using NVivo 10 and analysed thematically. ${ }^{51}$ Deductive and inductive coding of document data was conducted by ER, with transcript coding conducted by ER and SP. This initially involved scrutinising transcripts line by line, and categorising data using the seven NHS principles published in its March 2011 constitution as a conceptual framework. ${ }^{34,52}$ An additional inductive category on civil-society advocacy was also included to capture potential responses to perceived inequities. Coding was then reviewed by HLQ and $\mathrm{NH}$, disagreements resolved through coauthor discussion, and disconfirming data reported. Bias was reduced by involvement of more than one researcher in the analysis. HLQ and NH, both experienced qualitative researchers, checked codes and data to ensure views of participants were fairly represented.

The NHS principles were adopted as a framework because these are described in the NHS Constitution as guiding everything the NHS does and only changeable by government through 'a full and transparent debate with the public, patients and staff. ${ }^{\prime 4}$ The NHS was founded on the long-held ideal that good healthcare should be available to all, regardless of ability to pay. Three core principles, guiding the NHS since its 1948 launch, are meeting the needs of everyone, being free at delivery point, and being based on clinical need. Since 2000, these principles have been expanded and revised to seven (ie, comprehensive services for all, access based on clinical need, excellence and professionalism, patientcentred, organisational partnerships, value, accountability)..$^{34}$ Reporting adhered to RATS criteria for qualitative research. ${ }^{53}$

\section{Results}

Interviews were conducted with 22 participants; 16 vulnerable migrant service-users and 6 migrant health advocates (Table $3)$. Results are framed under the seven NHS principles as described in the 2011 NHS Constitution and the theme of civil-society advocacy. ${ }^{34}$ Each principle and ways it was experienced or interpreted by study participants in the context of austerity is described using documentary/literature (under Documents) and interview (under Interviews) evidence. Austerity was a contextual factor for the experiences of migrants and advocates, but causality assessment was not attempted. Quotations were primarily chosen as illustrative of broader consensus, with any contradicting perspectives noted.

Principle 1. Comprehensive Services Available to All

Documents: This principle stipulates full care provision to all persons, regardless of background or orientation, respecting human rights and promoting equality. ${ }^{34}$ This has guided the NHS since it was founded in 1948, encompassing a "wider social duty to promote equality through the services it provides." ${ }^{34}$ No official requirement yet exists for GPs to require formal documentation during registration and they can register any patient who applies. However, new legislation on NHS cost recovery ${ }^{27}$ may encourage providers to preemptively request official proof of address and ordinary residency (eg, utility bills, passport) though these are not legally required. ${ }^{18}$

Interviews: Advocates stressed that all NHS services were meant to be available to those contributing to British society.

"The NHS was founded as a service for those who contributed 
to British society, economically, socially and culturally. It didn't come down to nationality in any way. The NHS is a population-based tool to socially benefit the UK as a whole" (NGO3).

Advocates noted that confusing administrative demands were already a major barrier.

"People try [to access services] and get turned away wrongly. And it might be they have just been told to come back with a passport, or it might be because you are not entitled to register. And it is quite difficult to have them register, because of administrative barriers" (NGO1).

Migrants similarly reported that many GP surgeries required formal documentation that migrants often did not have in order to register.

"They need papers like bank statements or residency in the area... So I have my release medical report in the detention saying that I need to see local GP, but it's really hard to register" (13F).

Principle 2. Access Based on Clinical Need, not Individual Ability-to-Pay

Documents: This principle stipulates that NHS services are free-of-charge, except in circumstances sanctioned by Parliament. Under current policy, initial GP services are free. However, follow-up GP appointments, community care, dental, pharmaceutical, and optical care will be subject to charges for those not 'ordinary residents. ${ }^{35,36} \mathrm{~A} \& \mathrm{E}$ will also be subject to charges. ${ }^{24}$ Therefore, migrants are entitled to access frontline services, but may be charged later or for additional services.

Interviews: Advocates stated that all migrants had a right to access healthcare.

"The most important thing is that people have access to the most essential healthcare when they need [it]" (NGO1).

Migrants frequently expressed fears of not being able to access or afford necessary healthcare.

"I thought when I get sick or something what will I do? Who will help me?” (4F).

Many migrants unable to register with a GP reported avoiding care - including secondary care only accessible through a GP (eg, antenatal and HIV services) - until they were critical enough to use emergency services.

"I never go to the GP or hospital, I went to the Boot's and I took this pregnancy test. So when I know I'm pregnant I went to the doctor, emergency straight away and they write a letter to me to see the doctor, to check everything... And if I will get the letter from here [referral letter from DoW] I will go back to the hospital and get this scan" (4F).

Principle 3. Aspiring to the Highest Standards of Excellence and Professionalism

Documents: This principle stipulates that respect, dignity, compassion, and care are at the core of how NHS service-users and staff are treated. ${ }^{34}$ Services should support all sections of society to enjoy a good quality of life, using a proactive approach to overcome barriers to inclusion. ${ }^{22}$

Interviews: Almost all migrants reported positive experiences of NHS providers and satisfaction once registered with a GP.

"She is one of the best GPs I ever met, she's really good, and if she could help to make my life new again she would. Because anytime I go and see her she makes sure I get the treatment that I need" (15M).

Only one reported a negative or 'unprofessional' interaction with her GP. However, while challenging at first, this changed as they got to know each other and resulted in a relationship she identified as positive and caring.

"When I went...the doctor shouted at me and said 'You can't spend ten years without any treatment! Now where do you want me to begin?' He shouted at me and I just sat and looked at him and he calmed down.[...] I thought I shouldn't even come back again, I wanted to come back and tell the ladies here that I'm not going to continue with them. But then because he gave me an appointment, and when they checked all the tests I went for that appointment he was a different man, he was so calm, he treated me so well. And everything they have done they are OK" $(12 \mathrm{~F})$.

\section{Principle 4. Patient-Centred}

Documents: This principle stipulates NHS intentions to support individuals to promote and manage their own health, coordinated around their needs and preferences. ${ }^{22,34}$ This often means referral to counselling, physiotherapy, or other specialist services, but also the expectation that migrants be responsible for follow-up and navigating the system.

Interviews: Migrant participants focused on positive elements of patient-centred healthcare. For example, several reported being helped with addictions, provided with counselling, and having someone to 'listen to their problems.' Once in the system, support was reported as "very, very good" (4F).

While none directly mentioned difficulties navigating the system, many migrants reported issues with gatekeepers (eg, receptionists), including language barriers and disrespectful treatment.

"At the beginning it was so bad because when I went, right from reception they were asking me questions about 'When did you come? Who is your GP?' I said 'I don't have a GP, and they started shouting..." (12F).

However, some reported aggressive behaviours from healthworkers in their home countries and said the NHS system, particularly clinical providers, seemed more supportive.

"The nurses and doctors in Africa they shout at you, you know they're very aggressive. But here whenever you ask the doctor and nurse, they tell you, and I understand what they tell you. The way they are handling you is different" (14F).

\section{Principle 5. Organisational Partnerships}

Documents: This stipulates the NHS commitment to working jointly with partners to deliver improvements in health and well-being. ${ }^{34}$ While this principle is worded positively, the new charging guidelines require liaising with other organisations to help determine entitlement to free services. Lack of clarity as to how this will be managed has led to concerns about information being shared with police or immigration officials. ${ }^{27,31,38}$ Proposed reforms have increased concerns over data protection and confidentiality of patient records. ${ }^{54}$

Interviews: Advocates indicated that information sharing was a concern among migrants. Several stated that risks from violating patient confidentiality through data sharing were potentially life-threatening (eg, because vulnerable migrants feared deportation as much/more than potential health risks) 
and individuals would likely delay or forgo healthcare to avoid this risk.

"There is no way that anyone without regular status, or even with concerns about their immigration status (they may be regular but often people are quite unclear and would rather play safe), expose themselves to any risk that would have a huge deterrent effect on communities that they should be going to seek care when they need it. So we strongly oppose increasing data sharing. And we are quite concerned if it happens" (NGO2).

A major barrier to seeking healthcare reported by advocates and migrants was fear of being arrested.

"Some undocumented migrants avoid seeking care because they fear being reported to the authorities, being arrested or even being expulsed from the host country" (NGO1).

\section{Principle 6. Best Value for Taxpayer Money}

Documents: This principle stipulates that public healthcare funds are devoted solely to benefit those the NHS serves. ${ }^{34}$ However, debate exists around who the NHS serves (ie, only legal residents or all those in need). ${ }^{34}$ Some respondents to a 2013 Home Office consultation indicated NHS rules were 'too generous' and migrants should contribute towards care they receive, ${ }^{35}$ while the European Union (EU) Agency for Fundamental Rights stated healthcare provisions for irregular migrants should not be limited to emergency care. ${ }^{55}$

Interviews: Advocates highlighted the need to provide health services on both economic and moral grounds, to reduce vulnerability and exploitation.

"Research indicates that irregular migrants work and often times are paying tax through false national insurance. Some cases I would say, are making tax contribution, and you know are often working hard in more than one job, on very low pay, in quite exploitative situations, and I think, you know, forget about all the cost arguments and fairness arguments. From the health point of view, there are groups that should be priority in my view or being able to access care, because they exist outside the system and have potential vulnerability to exploitation, and likelihood of health issues" (NGO2).

\section{Principle 7. Accountability}

Documents: This stipulates that while government sets the framework, decisions about individual treatment services, are taken by the local NHS and the system of accountability should be transparent and clear. ${ }^{34}$ The NHS acknowledged NGO contributions: "As resources continue to be scarce across the health and care system, collaboration and partnership between statutory services and the VCSE [Voluntary Community and Social Enterprise] sector is becoming ever more critical."56 However, coordination and accountability mechanisms remain vague.

Interviews: Several advocates indicated that one challenge in advocating healthcare for migrants, was the difficulty of building a strong evidence base, as many issues are hidden or under-researched.

"There is only some little pieces of research, but there hasn't been a comprehensive picture, because NGOs often have low capacity and are covering lots of different issues" (NGO2).

Migrants indicated that responsibilities and accountability were often not clear to them. They reported seeking support from NGOs in accessing healthcare and relying on them rather than NHS staff to explain and help them navigate the health system.

"Somebody told me about this Doctors of the World, that they are helping to register. So I came here and then it's just easy..." (4F).

\section{Civil-Society Advocacy}

Documents: Advocacy is one response to perceived inequities. A characteristic of democratic societies is they benefit from independent not-for-profit advocacy organisations. Such organisations are important in amplifying civil-society concerns around potentially discriminatory legislation. Health advocacy is one example of giving voice to marginalized populations and communicating their priorities to decision-makers. ${ }^{57}$ Opinions differ on what is meant by 'advocacy', its desired outcomes, and measures to determine its effectiveness. Health advocacy has two main goals: (i) protection of the vulnerable or discriminated against and (ii) empowering those who need a stronger voice. ${ }^{58}$

Interviews: For advocates, the main goal was giving voice to marginalised people and their experiences.

"For us, advocacy is describing the needs that we see in our clinic, giving vulnerable populations the voice with government. So it's about basically enabling hidden experiences to be voiced, and with people who influence power" (NGO1).

However, advocates indicated they were careful how they iterated migrant rights to healthcare access.

"There is no international right to have free access to healthcare in any country and in fact the UK is quite unusual in its operation of free universal healthcare systems. So, we have to be quite careful when using the language of rights in that way, but I think there are certainly arguments to be made that if the system is designed in a way that blocks certain groups from receiving access to healthcare, that could either be life-threatening or detrimental to the livelihood of their children, that would violate international human rights agreements and obligations on the UK's part" (NGO2).

\section{Discussion}

Results provide vulnerable migrants' views of the British healthcare system and the challenges they experience accessing healthcare within the broader context of changes to immigration laws that have the potential to make access more difficult. Migrants indicated that administrative demands and ad-hoc paperwork requirements created confusion and fear, leading to avoidance or delays accessing healthcare. Once with a GP, migrants reported positive experiences with clinical services, though some noted receptionists and other gatekeepers as difficult. Several described the support of NGOs in navigating healthcare access, a finding supported by the literature..$^{30,57,59}$ All migrant participants stated that austerity measures would reduce their ability to access healthcare and no disconfirming evidence was found regarding the principles of availability of services and access based on clinical need.

A strength of this research lies in its focus on conveying the voices of vulnerable migrants and health advocates in Britain, which are relevant for current national debate on healthcare 
alterations and broader global debate on migration and health. Sustainable solutions can only be developed through involvement of all stakeholders. Describing the experiences of those directly affected by policy changes enables a deeper and more nuanced policy debate.

\section{NHS Principles}

Whether new reforms infringe human rights is hotly debated, but they do appear to counter NHS principles. ${ }^{17}$ Participant accounts agreed with NHS principles 1-2 regarding NHS comprehensiveness and accessibility based on clinical needs. While existing services provision had limitations, accounts of those accessing services were positive. However, ongoing reforms are increasing barriers (eg, Immigration Act implementation revised the 'ordinarily resident' definition to reduce conflict with Principle $1^{25}$ ) and raise concerns over data protection and patient confidentiality. ${ }^{24}$ Vulnerable individuals already delay or forgo healthcare or struggle to accommodate healthcare gatekeepers (eg, 102 of 180 eligible service-users in London Tower Hamlets in 2010 were refused registration because of restrictive identification requirements, including proof of immigration status). ${ }^{20} \mathrm{NHS}$ principles are a strength and admired by other countries hoping to advance the universal health coverage agenda ${ }^{60}$ This study highlights threats to NHS principles from austerity-related legislation (eg, Immigration Act), but broader influences on the universal healthcare agenda and health as soft power for diplomacy should also be considered. ${ }^{61}$ The United Kingdom could potentially lose some of its reputation and global influence in the new Sustainable Development Goals and universal coverage agenda, if it no longer promotes these ideals at home.

Healthcare Access for Vulnerable Migrants Under Austerity Vulnerable migrant experiences of NHS services are affected by ambiguities surrounding access entitlements and planned reforms. ${ }^{29,32,41,62}$ Results were consistent with studies by Mladovsky and others that migrants are confused about host country health systems and entitlements. ${ }^{29,40,62}$ Several issues warrant improvement, including accessibility, communication, and clarity on migrant entitlements and GP responsibilities. ${ }^{18,58,63}$

Concerns have been raised about potential public health impacts $^{25}$ and the human impact of changes to NHS entitlements and charging policy (eg, consequences of forcing health-workers to 'police' access, the extent changes may violate patient confidentiality or human rights). ${ }^{28}$ In principle, NHS rules on health service entitlement do comply with international conventions on access, though some migrants will be charged for the care they receive. However, the DoH acknowledges that rules are complex, allowing considerable confusion as to their appropriate application and variation in their interpretation by patients and healthcare providers. ${ }^{25}$ Participants reported being requested for documentation to justify entitlements, though there is no official requirement for documentation when registering with a GP. These ambiguities appear to hinder access for those in need and effective care by those providing services.

Experiences in other EU countries introducing similar proposals, such as Spain, indicate that increased bureaucratic barriers to healthcare access resulted in many with rights to healthcare not accessing services. ${ }^{64}$ There are also suggestions that although HIV and tuberculosis treatment is still available for non-residents as part of public health provision, many have discontinued or do not access treatment, for fear of being charged or deported. ${ }^{64,65}$ The Spanish government announced in 2015 that undocumented migrants will again have free healthcare, after A\&E wards became saturated in response to the austerity measure. ${ }^{6}$ Learning from the Spanish experience, proposed NHS changes are a potential setback for prevention, monitoring, and control of infectious and noninfectious diseases. ${ }^{67}$

\section{Limitations}

Although working with DoW allowed access to hard-to-reach vulnerable migrants who otherwise might not have been accessible, limitations exist in sampling strategy and size. Sample size was limited due to time constraints and challenges accessing vulnerable migrant service-users and busy, parttime NGO staff. Researchers did not have an interpreter so only migrants who spoke English or were accompanied by someone who could interpret were interviewed. This may have excluded differing views from migrants who did not speak English. Three migrants requested to speak through nonprofessional interpreters, potentially biasing their results. However, transcripts appeared similar to others when compared. Use of purposive and snowball sampling, while necessary for access, may have affected generalisability of results. For example researchers sampled vulnerable serviceusers from a clinic supporting migrants with difficulties accessing healthcare. Thus, views of migrants who did not access support, whether because they did not need or did not know about it, were not represented. Finally, causality between the context of austerity and issues identified in this research cannot be assumed.

\section{Conclusion}

Migrants and advocates report ongoing difficulties accessing healthcare. Proposals to restrict access to NHS care based on immigration status will likely worsen equity and potentially compromise the health of vulnerable individuals. NHS rules on health service entitlements comply with international conventions on access. However, rules are complex, creating confusion and varying interpretations by service-users and providers. Authors recommend that the British government reconsider NHS access restrictions based on immigration status due to: (i) the dearth of evidence supporting extensive services misuse and 'health tourism,' (ii) confusion and increased administrative complexity over entitlements, and (iii) the potential for reforms to threaten NHS principles of equity and access.

\section{Acknowledgements}

Authors thank study participants for their time and DoW UK for use of their facilities during interviewing. This research received no funding from any agency in the public, commercial, or not-for-profit sectors.

Ethical issues

Ethics approval was provided by the Research Ethics Committee of the London School of Hygiene and Tropical Medicine, London, UK. Participants received 
an information sheet and gave written informed consent after their questions were addressed. Anonymity and confidentiality were ensured through usage of identification codes and password-protected data storage.

\section{Authors' contributions}

ER conceived the study and with SP contributed to data collection, analysis, and manuscript drafting. HLQ and NH contributed to data interpretation and critically revised the manuscript. All authors approved the version for submission.

\section{Competing interests}

Authors declare that they have no competing interests.

\section{Authors' affiliations}

${ }^{1}$ Faculty of Public Health and Policy, London School of Hygiene and Tropical Medicine, London, UK. ${ }^{2}$ Saw Swee Hock School of Public Health, National University of Singapore, Singapore, Singapore.

\section{References}

1. Vickers T. Refugees, Capitalism and the British State: Implications for social workers, volunteers and activists. London: Ashgate; 2012.

2. Summers D. David Cameron warns of 'new age of austerity.' Guardian. April 26, 2009.

3. Borisch B. Public health in times of austerity. J Public Health Policy. 2014;35(2):249-257. doi:10.1057/jphp.2014.7

4. Deep End Report. GP experience of the impact of austerity on patients and general practices in very deprived areas. General Practice and Primary Care, Institute of Health and Wellbeing; 2012.

5. Roberts A, Marshall L, Charlesworth A. A decade of austerity? The funding pressures facing the NHS from 2010/11 to 2021/22. London: Nuffield Trust; 2012.

6. HM Treasury. Spending Review and Autumn Statement 2015. London; 2015.

7. Stuckler D, Basu S. The Body Economic: Why Austerity Kills. London: Basic Books; 2013.

8. Mind The Gap: Reducing Inequalities In Health And Health Care. Social and Public Health Sciences Unit website. http://www. sphsu.mrc.ac.uk/news/mind-the-gap-reducing-inequalities-inhealth-and-health-care.html. Published October 9, 2014.

9. Salway S, Mir G, Turner D, Ellison GT, Carter L, Gerrish K. Obstacles to "race equality" in the English National Health Service: Insights from the healthcare commissioning arena. Soc Sci Med. 2016;152:102-110. doi:10.1016/j.socscimed.2016.01.031

10. Salway S, Turner D, Mir G, et al. Towards equitable commissioning for our multiethnic society: a mixed-methods qualitative investigation of evidence utilisation by strategic commissioners and public health managers. Southampton (UK); 2013.

11. Higginbottom G, Reime B, Bharj K, et al. Migration and maternity: insights of context, health policy, and research evidence on experiences and outcomes from a three country preliminary study across Germany, Canada, and the United kingdom. Health Care Women Int. 2013;34(11):936-965. doi:10.1080/07399332. 2013.769999

12. Kyriakides $C$, Virdee $S$. Migrant labour, racism and the British National Health Service. Ethn Health. 2003;8(4):283-305. doi:10 $.1080 / 13557850310001631731$

13. Ali N, Atkin $\mathrm{K}, \mathrm{Neal} \mathrm{R}$. The role of culture in the general practice consultation process. Ethn Health. 2006;11(4):389-408. doi:10.1080/13557850600824286

14. Atkin $\mathrm{K}$, Bradby $\mathrm{H}$, Harding $\mathrm{S}$. Migrants and the key role that they play in what has been termed the age of migration. Ethn Health. 2010;15(5):435. doi:10.1080/13557858.2010.516646

15. Gunaratnam Y. Cultural vulnerability and professional narratives. J Soc Work End Life Palliat Care. 2011;7(4):338-349. doi:10.108

\section{0/15524256.2011.623464}

16. Gunaratnam Y. Intercultural palliative care: do we need cultural competence? Int J Palliat Nurs. 2007;13(10):470-477. doi:10.12968/ijpn.2007.13.10.27477

17. Hiam L, McKee M. Making a fair contribution: is charging migrants for healthcare in line with NHS principles? $J R$ Soc Med. 2016. doi:10.1177/0141076816638657

18. Poduval S, Howard $\mathrm{N}$, Jones L, Murwill $\mathrm{P}$, McKee $\mathrm{M}$, Legido-Quigley $H$. Experiences among undocumented migrants accessing primary care in the United Kingdom: a qualitative study. Int J Health Serv. 2015;45(2):320-333. doi: $10.1177 / 0020731414568511$

19. Craig G. 'Cunning, unprincipled, loathsome': the racist tail wags the welfare dog. J Soc Policy. 2007;36(4):605-623.

20. Rechel B, Mladovsky P, Ingleby D, Mackenbach JP, McKee $M$. Migration and health in an increasingly diverse Europe. Lancet. 2013;381(9873):1235-1245. doi:10.1016/S01406736(12)62086-8

21. Phillimore J. Approaches to health provision in the age of superdiversity: Accessing the NHS in Britain's most diverse city. Crit Soc Policy. 2011;31(5):5-29.

22. Department of Health (DoH). Departmental Report 2006: The Health and Personal Social Services Programmes. Norwich: DoH; 2006.

23. Thai K, Wimberley E, McManus S. Handbook of international health care systems. CRC Press; 2002:261-286.

24. British Medical Association (BMA). Access to health care for asylum seekers and refused asylum seekers-guidance for doctors. Medical Ethics Department, British Medical Association; 2012.

25. Department of Health (DoH). Visitor \& Migrant NHS Cost Recovery Programme Implementation Plan 2014-16. London: DoH; 2014.

26. UK Government. Pay for UK healthcare as part of your immigration application. https://www.gov.uk/healthcareimmigration-application/pay. Accessed December 1, 2015. Published 2015.

27. DoH. Guidance on implementing the overseas visitor hospital charging regulations 2015. London: Department of Health; 2015.

28. Powell T. NHS Charges for Overseas Visitors - Commons Library Standard Note2013.

29. Szczepura A. Access to health care for ethnic minority populations. Postgrad Med J. 2005;81:141-147. doi:10.1136/ pgmj.2004.026237

30. Chauvin P, Simonnot N, Douay C, Vanbiervliet F. Access to healthcare for the most vulnerable in a Europe in social crisis: focus on pregnant women and children. London: Doctors of the World; 2014.

31. Shangase P, Egbe CO. Barriers to Accessing HIV Services for Black African Communities in Cambridgeshire, the United Kingdom. J Community Health. 2014. doi:10.1007/s10900-0149889-8

32. Aung NC, Rechel B, Odermatt P. Access to and utilisation of GP services among Burmese migrants in London: a crosssectional descriptive study. BMC Health Serv Res. 2010;10:285. doi:10.1186/1472-6963-10-285

33. Dyson S. Genetic screening and ethnic minorities. Critical Social Policy. 1999;19:195-215. doi:10.1177/026101839901900204

34. NHS. The NHS Constitution: The NHS belongs to us all. London: Department of Health; 2013.

35. Home Office. Controlling Immigration - Regulating Migrant Access to Health Services in the UK Consultation document. London: Home Office; 2013.

36. Baker C, Stevenson J, Lewis S, Gallagher A. Migrant Access to the NHS: The Health Impact of the Immigration Bill and Changes 
to NHS Charging Policies. London: African Health Policy Network; 2014.

37. Hanefeld J, Horsfall D, Lunt N, Smith R. Medical tourism: a cost or benefit to the NHS? PloS One. 2013;8:e70406. doi:10.1371/ journal.pone.0070406

38. Oliver $\mathrm{C}$, Jayaweera $\mathrm{H}$. The Impacts of Restrictions and Entitlements on the Integration of Family Migrants: A Comparative Report. Oxford: COMPAS; 2013.

39. House of Lords. Ordinary residence ( $R-v$ - Barnet $L B C$ ex parte Shah [1983] 1 All ER 226). London: UK Goverment; 1983.

40. Woodward A, Howard N, Wolffers I. Health and access to care for undocumented migrants living in the European Union: a scoping review. Health Policy Plan. 2014;29(7):818-830. doi:10.1093/ heapol/czt061

41. Norredam ML, Nielsen AS. Migrants ' access to healthcare secondary publication. Dan Med Bull. 2007;54(1):48-9

42. Katikireddi S, Bhopal R, Quickfall J. GPs need training and funding in caring for refugees and asylum seekers. BMJ. 2004;328(7442):770.

43. Papadopoulos I, Lees S, Lay M, Gebrehiwot A. Ethiopian refugees in the UK: migration, adaptation and settlement experiences and their relevance to health. Ethn Health. 2004;9:55-73. doi:10.1080/1355785042000202745

44. Aspinall P. Inclusive Practice: Vulnerable Migrants, Gypsies and Travellers, People Who Are Homeless, and Sex Workers: A Review and Synthesis of Interventions/Service Models that Improve Access to Primary Care \& Reduce Risk of Avoidable Admission to Hospital. Data and Research Working Group of the Inclusion Health Programme; 2014.

45. Ponterotto J. Qualitative research in multicultural psychology: Philosophical underpinnings, popular approaches, and ethical considerations. Cultur Divers Ethnic Minor Psychol. 2010;16:581-589.

46. Creswell J. Research design: Qualitative, quantitative, and mixed methods approaches. London and Thousand Oaks: Sage Publications; 2009.

47. Kincheloe J, McLaren P. Rethinking critical theory and qualitative research. In: Lincoln NDY, ed. Handbook of Qualitative Research. 2nd ed. Thousand Oaks: Sage; 2000.

48. Ulin PR, Robinson ET, Tolley EE. Qualitative Methods in Public Health. Med Sci Sports Exerc. 2005;37(7):1249. doi:10.1249/01. mss.0000172593.20181.14

49. Ponterotto J, Mathew J, Raughley B. The Value of Mixed Methods Designs to Social Justice Research in Counseling and Psychology. J Soc Action Couns Psychol. 2013;5(2):42-68.

50. Trainor A. Interview research. In: Trainor A, Graue E, eds. Reviewing Qualitative Research in the Social Sciences. London: Routledge; 2013.

51. Ritchie J, Spencer L. Qualitative data analysis for applied policy research. In: Bryman A, Burgess R, eds. Analysing Qualitative Data. London: Routledge; 1994:173-194.
52. Saldaña J. The Coding Manual for Qualitative Researchers. London: Sage; 2009.

53. Clark JP: How to peer review a qualitative manuscript. In: Godlee F, Jefferson T, eds. Peer Review in Health Sciences. 2nd ed. London: BMJ Books; 2003:219-235.

54. Ball J. Home Office accessing NHS records to help track down illegal immigrants. The Guardian. July 13, 2014. http://www. theguardian.com/uk-news/2014/jul/13/home-office-nhs-recordsillegal-immigrants

55. Hunt J. Doctors of the World. UK; 2013.

56. DoH, NHS England, Public Health England, VCSE sector. Joint review of health and care sector investment in Voluntary Community and Social Enterprise organisations. Voluntary Community Social Enterprise Review website: Voluntary Sector Health and Care, Department of Health; 2014.

57. Macadam A, Watts R. The Impact of Advocacy For People Who Use Social Care Services. London: NDTi; 2013.

58. Carlisle S. Health promotion, advocacy and health inequalities: a conceptual framework. Health Prom Int. 2000;15(4):369-376. doi:10.1093/heapro/15.4.369

59. Easton A, Atkin K, Hare P. 'A light in a very dark place': the role of a voluntary organisation providing support for those affected by encephalitis. Neuropsychol Rehabil. 2007;17(4-5):638-647. doi:10.1080/09602010601155205

60. Chalkidou K, Vega J. Sharing the British National Health Service around the world: a self-interested perspective. Global Health. 2013;9:51.

61. Kickbusch I, Lister G, Told M, Drager N, eds. Global health diplomacy: Concepts, issues, actors, instruments, fora and cases. New York: Springer; 2013.

62. Mladovsky P. A framework for analysing migrant health policies in Europe. Health Policy. 2009;93:55-63. doi:10.1016/j. healthpol.2009.05.015

63. World Health Organization (WHO). How health systems can address health inequities linked to migration and ethnicity. Copenhagen: WHO Regional Office for Europe; 2010.

64. Legido-Quigley H, Urdaneta E, Gonzalez A, et al. Erosion of universal health coverage in Spain. Lancet. 2013;382(9909):1977. doi:10.1016/s0140-6736(13)62649-5

65. Legido-Quigley H, Otero L, la Parra D, Alvarez-Dardet C, MartinMoreno JM, McKee M. Will austerity cuts dismantle the Spanish healthcare system? BMJ. 2013;346:f2363. doi:10.1136/bmj. f2363

66. Badcock J. Spain to allow illegal immigrants to access free public healthcare. The Telegraph. April 1, 2015. http://www.telegraph. co.uk/news/worldnews/europe/spain/11509227/Spain-to-allowillegal-immigrants-to-access-free-public-healthcare.html

67. Kentikelenis A, Karanikolos M, Williams G, et al. How do economic crises affect migrants' risk of infectious disease? A systematic-narrative review. Eur J Public Health. 2015;25(6):937944. doi:10.1093/eurpub/ckv151 